\title{
BMJ The 5-minute Apgar score as a predictor Open of childhood cancer: a population-based cohort study in five million children
}

\author{
Jiong Li, ${ }^{1}$ Sven Cnattingus, ${ }^{2}$ Mika Gissler, ${ }^{3}$ Mogens Vestergaard,,${ }^{4,5}$ \\ Carsten Obel, ${ }^{4,6}$ Jette Ahrensberg, ${ }^{5}$ Jørn Olsen, ${ }^{17}$
}

To cite: Li J, Cnattingus S, Gissler M, et al. The 5-minute Apgar score as a predictor of childhood cancer: a population-based cohort study in five million children. BMJ Open 2012;0:e001095. doi:10.1136/bmjopen-2012001095

- Prepublication history and additional material for this paper are available online. To view these files please visit the journal online (http://dx. doi.org/10.1136/bmjopen2012-001095).

Received 1 March 2012 Accepted 2 July 2012

This final article is available for use under the terms of the Creative Commons Attribution Non-Commercial 2.0 Licence; see http://bmjopen.bmj.com

For numbered affiliations see end of article

Correspondence to Dr Jiong Li; jl@soci.au.dk

\section{ABSTRACT}

Objective: The aetiology of childhood cancer remains largely unknown but recent research indicates that uterine environment plays an important role. We aimed to examine the association between the Apgar score at 5 min after birth and the risk of childhood cancer.

Design: Nationwide population-based cohort study.

Setting: Nationwide register data in Denmark and Sweden.

Study population: All live-born singletons born in Denmark from 1978 to $2006(\mathrm{~N}=1771615)$ and in Sweden from 1973 to 2006 ( $N=3319$ 573). Children were followed up from birth to 14 years of age.

Main outcome measures: Rates and HRs for all childhood cancers and for specific childhood cancers.

Results: A total of 8087 children received a cancer diagnosis (1.6 per 1000). Compared to children with a 5-min Apgar score of 9-10, children with a score of 0-5 had a $46 \%$ higher risk of cancer (adjusted HR $1.46,95 \% \mathrm{Cl} 1.15$ to 1.89 ). The potential effect of low Apgar score on overall cancer risk was mostly confined to children diagnosed before 6 months of age. Children with an Apgar score of $0-5$ had higher risks for several specific childhood cancers including Wilms' tumour (HR $4.33,95 \% \mathrm{Cl} 2.42$ to 7.73 ).

Conclusions: A low 5 min Apgar score was associated with a higher risk of childhood cancers diagnosed shortly after birth. Our data suggest that environmental factors operating before or during delivery may play a role on the development of several specific childhood cancers.

\section{INTRODUCTION}

Childhood cancer is the second leading cause of deaths in children in high-income countries, and is of major concern for patients, families and societies. ${ }^{12}$ In spite of extensive research, little is known about the aetiology of childhood cancer. ${ }^{1}{ }^{2}$ Almost half of childhood cancers are diagnosed before 5 years of age, ${ }^{1}$ indicating that some of the causal factors operate in utero or in early postnatal life. ${ }^{3}{ }^{4}$ However, only few such risk factors have been identified. ${ }^{5}$ Birth

\section{ARTICLE SUMMARY}

Article focus

- The aetiology of childhood cancer remains largely unknown but recent research indicates that uterine environment plays an important role.

- The Apgar score may have more implications than its role in current clinical practice.

Key messages

- A low 5 min Apgar score was associated with a higher risk of childhood cancer, suggesting that environmental factors operating before or during delivery may play a causal role.

- In addition to as an assessment tool for a newborn's clinical status, the Apgar score at $5 \mathrm{~min}$ may also indicate programming effect of fetal environment on diseases in later life, including childhood cancer.

Strengths and limitation of this study

- The most important strengths of our study include singletons in a prospectively longitudinal design, large sample size of five million, complete follow-up, accurate data on Apgar score and cancer diagnosis and detailed data on covariates.

- The limitations of our study are that we lack information on risk factors after birth and the case numbers for several childhood cancers are small.

characteristics may represent the interactions between genetic susceptibility and prenatal environmental causes, ${ }^{6-8}$ but the empirical evidence available to date is inconsistent and inconclusive. $^{6-9}$

The Apgar score, which is assigned to virtually every newborn, evaluates the clinical state of the newborns based on five physical signs (heart rate, respiratory effort, reflex irritability, muscle tone and colour) present shortly after birth. ${ }^{10}$ A total score of 9 or 10 indicates that the baby is 'in its best possible condition'. ${ }^{10}$ Although the usefulness of the Apgar score has been questioned in recent 
years, ${ }^{11}$ this scoring system remains the only widely used and accepted tool for assessing the vitality of newborn infants across the world. ${ }^{12}{ }^{13}$ The 5 min Apgar score is a predictor of neonatal mortality, ${ }^{14}$ and several neurological outcomes. ${ }^{15-19}$ A suboptimal fetal environment ${ }^{20}$ related to a low Apgar score may also be associated with compromised immune responses against tumours, ${ }^{21}$ which can predict long-term health problems, ${ }^{22}{ }^{23}$ including future cancer risk.

In this population-based cohort study, we examined the association between the Apgar score at 5 min of age and childhood cancer, after taking other birth characteristics, ${ }^{8}{ }^{24}$ maternal socio-demographic characteristics, ${ }^{12}$ and maternal smoking during pregnancy ${ }^{25} 26$ into account. We hypothesised that children with a low Apgar score have a higher risk of childhood cancer than children with an optimal Apgar score. ${ }^{21}$

\section{METHODS}

\section{Study design and study population}

Data from eight national registers in Sweden and Denmark were linked by the unique personal identification number, which is assigned to each resident in the Scandinavian countries. ${ }^{27}$ This population-based cohort study $^{28}$ included all singleton children born in Denmark from 1978 to 2006 ( $\mathrm{N}=1771615)$ and in Sweden from 1973 to 2006 (N=3 319 573). Children were followed from birth until a cancer diagnosis, death, emigration, 14 years of age or end of follow-up (31 December 2006 in Sweden and 31 December 2007 in Denmark), whichever came first. The 610 children who had a birth defect and a cancer diagnosis were excluded, as some birth defects are closely associated with childhood cancers. The final study population included 5091188 children.

The Apgar score at $5 \mathrm{~min}$ of age and other birth characteristics (gestational age, birth weight, etc) were retrieved from Medical Birth Registers (MBR) in Denmark and in Sweden. The Danish Medical Birth Register was established in $1968^{29}$ and the Swedish Medical Birth Register in 1973 (http://www.socialstyrelsen.se/Lists/Artikelkatalog/ Attachments/10655/2003-112-3_20031123.pdf). These registers include data on practically all deliveries in Denmark and Sweden, respectively, and the information is collected from medical records in prenatal, delivery and neonatal care. It is compulsory for every healthcare provider to report to the registers. ${ }^{30}$

Socio-demographic factors were obtained from the Danish Integrated Database for Longitudinal Labor Market Research (IDA), the Danish Civil Registry System, the Swedish Education Registry and the Swedish Registry of Population and Population Changes. ${ }^{28}$

\section{Outcome measurements}

Data on cancer were obtained from national cancer registries, and the registration and coding practices have been described elsewhere. ${ }^{31} 32$ The main outcomes of interest were all incident cancers (ICD-7 codes 104-205, ICD-10 codes C00-97) diagnosed before 15 years of age and the most frequent childhood cancers for which uterine environment has been suggested to play a role: ${ }^{3} 46-9$ leukaemias (ICD-7 code 204, ICD-10 codes C91-95), lymphomas (ICD-7 code 201-203, ICD-10 code C81-C85), brain and nervous system tumours (ICD-7 code 193, ICD-10 codes C70-C72, C47, C74.1), retinoblastoma (ICD-7 code 192 and PAD 436, ICD-10 code C69.2), Wilms' tumour (ICD-7 code 180 and PAD 886, ICD-10 code C64.9), hepatoblastoma (ICD-7 code 155, ICD-10 code C22), malignant bone tumours (ICD-7 code 196, ICD-10 codes C40-C41) and testicular cancer (ICD-7 code 178, ICD-10 code C62).

\section{Statistical analysis}

All data handling and statistical analyses were performed using SAS V.9.2 statistical software package (SAS Institute, Inc, Cary, North Carolina, USA). The low Apgar score was categorised into each single score and also into two subgroups (0-5 and 6-8), as a very low score would be different from a score of over $5 .{ }^{10}$ HRs with $95 \%$ CIs were estimated by Cox regression with the PHREG procedure. Potential confounders were included in the model, such as country (Denmark and Sweden), child sex (male and female) and birth characteristics (parity $(1,2$ and $\geq 3)$, birth weight $(<2500$, 2500-3249, 3250-3999 and $\geq 4000 \mathrm{~g})$, gestational age ( $<37$ and $\geq 37$ weeks), maternal factors (age $(\leq 26,27-30$ and $\geq 31$ years), education level (low: $\leq 9$, middle: $10-14$ and high: $\geq 15$ years) (available Swedish data from 1990, 1995, 2000 and 2005, available annual Danish data from 1978 to 2006) and $^{29}$ smoking during pregnancy (yes, no) (available 1991-2007 in Denmark and 1983-2006 in Sweden)).

Analyses were performed when we excluded children diagnosed with cancer before 6 months of age to see how the overall effect of a low Apgar score would change when most embryonic cancers are excluded. We also repeated our analyses by dropping Wilms' tumour, hepatoblastoma, testicular cancer and retinoblastoma to see how the overall effect would be driven by these four childhood cancers.

Analyses were also stratified by country, sex, birth weight, gestational age and parity, which have been suggested to be associated with both Apgar score and cancer risk. ${ }^{12}$ Analyses were also performed for the subcohorts where information on maternal smoking was available.

\section{RESULTS}

The baseline characteristics of the study population (5061 798 singletons) are shown in table 1 according to the three subgroups of Apgar scores (0-5, 6-8 and 9-10). Low Apgar scores were comparable for most characteristics but more frequent among children born preterm or with low birth weight.

A total of 8087 children were diagnosed with cancer before 14 years of age (1.6 per 1000 children). Table 2 
Table 1 Baseline characteristics of the study population according to the Apgar score*

\begin{tabular}{|c|c|c|c|c|}
\hline \multirow[b]{2}{*}{ Variables } & \multicolumn{4}{|c|}{ Apgar score at $5 \mathrm{~min}$} \\
\hline & $0-5$ & $6-8$ & $9-10$ & Unknown \\
\hline \multicolumn{5}{|l|}{ Country } \\
\hline Denmark & $10673(1)$ & $42118(2)$ & $1669956(96)$ & $18868(1)$ \\
\hline Sweden & $22694(1)$ & 116167 (4) & 2951063 (90) & 229649 (7) \\
\hline \multicolumn{5}{|l|}{ Sex } \\
\hline Boys & $18829(1)$ & 89973 (3) & 2365951 (91) & $126011(5)$ \\
\hline Girls & $14537(1)$ & $68312(3)$ & $2255068(92)$ & $122506(5)$ \\
\hline \multicolumn{5}{|l|}{ Birth order } \\
\hline 1 & $16910(1)$ & $91199(4)$ & $1971064(90)$ & $100239(5)$ \\
\hline 2 & $9388(1)$ & $42290(2)$ & 1694866 (92) & $93228(5)$ \\
\hline$\geq 3$ & $5782(1)$ & $23091(2)$ & 894631 (92) & $484404(5)$ \\
\hline Unknown & $1287(2)$ & $1705(2)$ & $60458(86)$ & $6646(9)$ \\
\hline \multicolumn{5}{|l|}{ Gestational age } \\
\hline$<37$ weeks & $8902(4)$ & $27338(11)$ & $191552(79)$ & $14439(6)$ \\
\hline$>=37$ weeks & $22990(<1)$ & $129238(3)$ & 4368046 (92) & $226668(5)$ \\
\hline Unknown & $1475(2)$ & 1709 (2) & $61421(85)$ & 7410 (10) \\
\hline \multicolumn{5}{|l|}{ Birth weight (g) } \\
\hline$<2500$ & $8238(5)$ & 22489 (13) & $135895(76)$ & $11150(6)$ \\
\hline 2500-3249 & 7766 (1) & 39824 (3) & $1137398(91)$ & $62399(5)$ \\
\hline 3250-3999 & $10994(<1)$ & $65669(2)$ & 2448691 (92) & 128267 (5) \\
\hline$>=4000$ & $4340(<1)$ & $27736(3)$ & 833472 (92) & 37497 (4) \\
\hline Unknown & 2029 (3) & 2567 (3) & $65563(83)$ & $9204(12)$ \\
\hline \multicolumn{5}{|l|}{ Maternal age } \\
\hline$<=26$ & $12936(1)$ & $60051(3)$ & $1690721(90)$ & $120969(6)$ \\
\hline $27-30$ & $9293(1)$ & $45162(3)$ & 1378031 (92) & $68490(5)$ \\
\hline$\geq 31$ & $11134(1)$ & $53060(3)$ & $1552002(93)$ & $59009(4)$ \\
\hline Unknown & $4(1)$ & $12(4)$ & $265(83)$ & $39(12)$ \\
\hline \multicolumn{5}{|c|}{ Maternal education (years) } \\
\hline Low $(\leq 9)$ & $16346(1)$ & $72583(3)$ & $2006475(90)$ & $146220(7)$ \\
\hline Middle (10-14) & $8770(1)$ & 45007 (3) & 1296875 (92) & $52045(4)$ \\
\hline High $(\geq 15)$ & $5600(1)$ & $28120(3)$ & 908327 (93) & $36363(4)$ \\
\hline Unknown & $2651(1)$ & $12575(3)$ & $409342(93)$ & $13889(3)$ \\
\hline \multicolumn{5}{|c|}{ Maternal smoking during pregnancy } \\
\hline Yes & $4755(1)$ & $21254(3)$ & $633618(94)$ & $10935(2)$ \\
\hline No & $14661(1)$ & $85122(3)$ & $2419740(95)$ & $32303(1)$ \\
\hline Unknown & $2395(1)$ & $9514(4)$ & $222589(91)$ & $9968(4)$ \\
\hline
\end{tabular}

Table 2 HRs for childhood cancer according to the Apgar score at $5 \mathrm{~min}$

\begin{tabular}{lrll}
\hline Apgar score & Cases (rate per 1000) & Crude HR & Adjusted HR (95\% Cl) † \\
\hline 0 & $3(0.7)$ & $0.47(0.15$ to 1.45$)$ & $0.56(0.18$ to 1.73$)$ \\
1 & $15(2.9)$ & $2.44(1.47 \text { to } 4.04)^{*}$ & $2.17(1.31 \text { to } 3.60)^{*}$ \\
2 & $6(1.9)$ & $1.89(0.61$ to 3.54$)$ & $1.72(0.77$ to 3.82$)$ \\
3 & $9(2.1)$ & $1.85(0.96$ to 3.56$)$ & $1.67(0.87$ to 3.21$)$ \\
4 & $14(2.2)$ & $1.61(0.94$ to 2.78$)$ & $1.48(0.86$ to 2.55$)$ \\
5 & $21(2.1)$ & $1.40(0.91$ to 2.18$)$ & $1.32(0.85$ to 2.05$)$ \\
$0-5$ combined & $68(2.0)$ & $1.54(1.21 \text { to } 1.96)^{*}$ & $1.46(1.15 \text { to } 1.89)^{*}$ \\
6 & $28(1.5)$ & $1.03(0.71$ to 1.49$)$ & $0.95(0.66$ to 1.38$)$ \\
7 & $61(1.6)$ & $1.15(0.99$ to 1.34$)$ & $1.00(0.77$ to 1.29$)$ \\
8 & $177(1.7)$ & $1.18(1.08$ to 1.29$)$ & $1.08(0.93$ to 1.26$)$ \\
$6-8$ combined & $266(1.7)$ & $1.12(0.99$ to 1.27$)$ & $1.05(0.92$ to 1.18$)$ \\
$9-10$ & $7216(1.6)$ & $1.0($ ref) & $1.0($ ref $)$ \\
\hline
\end{tabular}

\section{${ }^{*} \mathrm{p}<0.05$.}

†Adjusted for country, sex, maternal factors at child birth (age, education and smoking during pregnancy) and birth characteristics of the child (birth weight, gestational age and birth order). 
presents that children with a score of $0-5$ had a higher overall rate of childhood cancer (2.0 per 1000) than those with a score of 6-8 (1.7 per 1000) and those with a score of 9-10 (1.6 per 1000). Compared to children with a 5 min Apgar score of 9-10, children with a score of $0-5$ had a $46 \%$ increased risk of cancer before 14 years of age (adjusted HR 1.46, 95\% CI 1.15 to 1.89 ), but children with a score of 6-8 had no increased risk of cancer (HR 1.05, 95\% CI 0.92 to 1.18 ).

Table 3 shows that the HRs in children according to age at cancer diagnosis. For cancer diagnosed before 6 months of age, an Apgar score of 0-5 was associated with sixfold overall risk (HR 6.04, 95\% CI 3.73 to 9.76) and an Apgar score of 6-8 was associated with a two-fold increase in risk (HR 2.17, 95\% CI 1.54 to 3.05). The most frequent diagnosed cancers during this period include tumours from brain/nervous system, endocrinal glands, kidney and leukaemia/lymphomas (data not shown). There were no statistically significant increased risks for cancer diagnosed after 6 months of age.

Compared to children with an Apgar score of 9-10, children with a score of $0-5$ had higher risks of several childhood cancers (CNS tumours, retinoblastoma, hepatic tumours, bone tumours and testicular tumours), but most estimates were not statistically significant (table 4). Low Apgar scores did not influence risks of lymphatic/ hemapoietic neoplasms. The highest HR was observed in children with a score of $0-5$ for Wilms' tumour (HR 4.33, 95\% CI 2.42 to 7.73 ).

When Wilms' tumour, testicular cancer, hepatic cancer and retinoblastoma were not included in the analyses, the estimates for overall effect of a low Apgar score are smaller but the risks remain elevated (data not shown). With these exclusions, the estimates for cancer diagnosed before 6 months were even slightly higher (data not shown) than those presented in table 3 . When we excluded cancers diagnosed during the first 6 months of life, a low Apgar score was not associated with increased overall cancer risk or with CNS cancer (data not shown). Estimates for other cancers, such as Wilms' tumour, remained essentially unchanged (data not shown).
The elevated risks related to an Apgar score of 0-5 were higher in almost all each stratum of the covariates, such as country (Denmark and Sweden), child sex (male and female) and birth characteristics (parity (1, 2 and $\geq 3$ ), birth weight $(<2500,2500-3249,3250-3999$ and $\geq 4000 \mathrm{~g})$, gestational age $(<37$ and $\geq 37$ weeks $)$ ), maternal factors (age $(\leq 26,27-30$ and $\geq 31$ years), education level (low: $\leq 9$, middle: $10-14$ and high: $\geq 15$ years) ${ }^{29}$ and smoking during pregnancy (yes, no)) (data not shown).

\section{DISCUSSION}

Children with a low 5 min Apgar score, especially children with a score of $0-5$, had a higher overall risk of childhood cancer that was diagnosed before 6 months of age. We also observed higher risks for several main childhood cancers like Wilms' tumour. The associations were independent of country, child sex, child birth characteristics (birth weight, birth order and gestational age) and maternal factors (age, education and smoking during pregnancy). However, we found no association between low Apgar score and risk of leukaemia and other lymphatic/haemapoietic malignancies.

The theory of 'developmental-origins of health and disease' proposes the importance of in utero environment for long-term human health. ${ }^{22}{ }^{23}$ We observed that children with a low Apgar score between 0 and 5 had a higher overall cancer risk than those with an optimal score (9 or 10). The mechanism underlying this observation is, however, unclear. A low Apgar score is a marker of a suboptimal fetal environment ${ }^{20}$ or other factors that prevent the child from achieving a high score. From a programming perspective, it is interesting to observe that the effect of a low Apgar score on overall cancer risk was the strongest for cancers diagnosed before 6 months of age. Tumours from brain/nervous system, endocrinal glands, kidney and leukaemia/lymphomas were among the most frequent diagnosed cancers during this period. This observation is in line with suggestions from previous studies that in utero exposures to insulin-like

Table 3 HRs for childhood cancer according to the Apgar score at $5 \mathrm{~min}$, by age at diagnosis

\begin{tabular}{|c|c|c|c|c|}
\hline Age at diagnosis & Apgar score & Cases (rate, \%०) & Crude HR $(95 \% \mathrm{Cl})$ & Adjusted HR (95\% Cl)† \\
\hline \multirow[t]{3}{*}{ Under 6 months } & $0-5$ & $20(0.6)$ & $6.65(4.15 \text { to } 10.65)^{*}$ & $6.04(3.73 \text { to } 9.76)^{*}$ \\
\hline & $6-8$ & $39(0.2)$ & $2.43(1.73 \text { to } 3.39)^{*}$ & $2.17(1.54 \text { to } 3.05)^{*}$ \\
\hline & $9-10$ & $465(0.1)$ & 1.0 (ref) & 1.0 (ref) \\
\hline \multirow{3}{*}{6 months -5 years } & $0-5$ & $25(0.9)$ & $1.21(0.82$ to 1.79$)$ & $1.18(0.80$ to 1.76$)$ \\
\hline & $6-8$ & $134(0.9)$ & $1.15(0.97$ to 1.36$)$ & 1.09 (0.92 to 1.30$)$ \\
\hline & $9-10$ & $3678(0.8)$ & 1.0 (ref) & 1.0 (ref) \\
\hline \multirow[t]{3}{*}{$>5$ years } & $0-5$ & $23(1.0)$ & $1.17(0.78$ to 1.77$)$ & $1.10(0.73$ to 1.65$)$ \\
\hline & $6-8$ & $93(0.7)$ & 0.89 (0.73 to 1.10$)$ & $0.83(0.67$ to 1.02$)$ \\
\hline & $9-10$ & $3223(0.8)$ & 1.0 (ref) & 1.0 (ref) \\
\hline
\end{tabular}

${ }^{*} p<0.05$.

†Adjusted for country, sex, maternal factors at child birth (age, education and smoking during pregnancy) and birth characteristics of the child (birth weight, gestational age and birth order). 
Table 4 HRs for main childhood cancers according to the Apgar score at 5 min

\begin{tabular}{|c|c|c|c|c|}
\hline Cancer type & Apgar score & $\begin{array}{l}\text { Cancer cases } \\
\text { (rate per 1000) }\end{array}$ & $\begin{array}{l}\text { Crude HR } \\
(95 \% \mathrm{Cl})\end{array}$ & $\begin{array}{l}\text { Adjusted HR } \\
(95 \% \mathrm{Cl})\end{array}$ \\
\hline \multirow[t]{3}{*}{ Leukaemia } & $0-5$ & $13(0.4)$ & $1.03(0.60$ to 1.79$)$ & $1.05(0.61$ to 1.81$)$ \\
\hline & $6-8$ & $71(0.5)$ & $1.02(0.81$ to 1.29$)$ & $1.02(0.80$ to 1.29$)$ \\
\hline & $9-10$ & $2122(0.5)$ & 1.0 (ref) & 1.0 (ref) \\
\hline \multirow[t]{3}{*}{ Lymphomas } & $0-5$ & $3(0.1)$ & $0.84(0.27$ to 2.60$)$ & $0.73(0.23$ to 2.27$)$ \\
\hline & $6-8$ & $12(0.1)$ & $0.62(0.35$ to 1.09$)$ & 0.51 (0.29 to 0.90$)$ \\
\hline & $9-10$ & $598(0.1)$ & 1.0 (ref) & 1.0 (ref) \\
\hline \multirow[t]{3}{*}{ Central nervous system cancers } & $0-5$ & $21(0.6)$ & $1.24(0.78$ to 1.98$)$ & $1.22(0.77$ to 1.94$)$ \\
\hline & $6-8$ & $104(0.7)$ & $1.29(1.06 \text { to } 1.57)^{*}$ & $1.26(1.03 \text { to } 1.54)^{*}$ \\
\hline & $9-10$ & $2432(0.5)$ & 1.0 (ref) & 1.0 (ref) \\
\hline \multirow[t]{3}{*}{ Retinoblastoma } & $0-5$ & $3(0.1)$ & $2.20(0.70$ to 6.84$)$ & 2.03 (0.64 to 6.39$)$ \\
\hline & $6-8$ & $4(<0.05)$ & $0.52(0.19$ to 1.39$)$ & 0.48 (0.18 to 1.28$)$ \\
\hline & $9-10$ & $240(0.1)$ & 1.0 (ref) & 1.0 (ref) \\
\hline \multirow[t]{3}{*}{ Wilms' tumour } & $0-5$ & $12(0.4)$ & $4.62(2.61 \text { to } 8.20)^{*}$ & $4.33(2.42 \text { to } 7.73)^{*}$ \\
\hline & $6-8$ & $18(0.1)$ & 1.24 (0.77 to 1.99$)$ & $1.16(0.72$ to 1.87$)$ \\
\hline & $9-10$ & $444(0.1)$ & 1.0 (ref) & 1.0 (ref) \\
\hline \multirow[t]{3}{*}{ Hepatoblastoma } & $0-5$ & $1(<0.05)$ & $1.78(0.25$ to 12.76$)$ & $1.51(0.21$ to 10.96$)$ \\
\hline & $6-8$ & $4(<0.05)$ & $1.27(0.47$ to 3.44$)$ & 1.06 (0.39 to 2.92$)$ \\
\hline & $9-10$ & $96(<0.05)$ & 1.0 (ref) & 1.0 (ref) \\
\hline \multirow[t]{3}{*}{ Bone cancer } & $0-5$ & $3(0.1)$ & 2.25 (0.72 to 7.02$)$ & 2.05 (0.65 to 6.45$)$ \\
\hline & $6-8$ & $6(<0.05)$ & 0.85 (0.38 to 1.90$)$ & $0.79(0.35$ to 1.80$)$ \\
\hline & $9-10$ & $220(0.1)$ & 1.0 (ref) & 1.0 (ref) \\
\hline \multirow[t]{3}{*}{ Testicular cancer } & $0-5$ & $0(0)$ & - & - \\
\hline & $6-8$ & $4(<0.05)$ & 2.08 (0.76 to 5.75$)$ & 1.89 (0.68 to 5.25$)$ \\
\hline & $9-10$ & $59(<0.05)$ & 1.0 (ref) & 1.0 (ref) \\
\hline
\end{tabular}

${ }^{*} p<0.05$.

†Adjusted for country, sex, maternal factors at child birth (age, education and smoking during pregnancy) and birth characteristics of the child (birth weight, gestational age and birth order).

growth factors, $^{8}$ oestrogens ${ }^{33} 34$ or infections ${ }^{24} 35$ may play a role for the relationships between other birth outcomes and many childhood cancers, or childhood cancer risk in general. A low Apgar score probably shares aetiology with cancers initiated in fetal life, and different biological pathways may operate for the association between Apgar score and childhood cancers. For example, neonatal treatments related to low Apgar scores may increase the risk of some childhood cancers. ${ }^{36} 37$

The best evidence for fetal origins of childhood cancer has been available for leukaemia. ${ }^{78}$ Our findings suggest that those observations may operate through the mechanisms that do not affect the Apgar score, and similar interpretations apply to other lymphatic/haemapoietic neoplasms. The associations between a low Apgar score and several other specific childhood cancers in our study are noteworthy. For example, the highest risk of a low Apgar score was obtained for Wilms' tumour, which is in line with observations in two register-based studies (restricted to only girls in one of the studies) ${ }^{39} 40$ but not in another case-control study. ${ }^{41}$ Hypoxia, as indicated by a low score, may result in cell damage that subsequently leads to Wilms' tumour. ${ }^{42} 43$ Alternatively, neonatal treatments provided to neonates with a low Apgar score may also increase the risk of Wilms' tumour. ${ }^{36} 37$ Hepatoblastoma is reported to be associated with factors like low birth weight, ${ }^{44}$ smoking during pregnancy or young maternal age. ${ }^{45}$ A recent study showed a reverse association between birth order and retinoblastoma. ${ }^{9}$ However, the observed elevated risks of both hepatoblastoma and retinoblastoma after adjustment might indicate an independent role of a low Apgar score for these two childhood cancers.

The observed associations between low Apgar scores and childhood cancer risk were not explained by other adverse birth outcomes, which have been widely used as the proxy indicators of fetal environment to explain fetal origins for a number of adult diseases. ${ }^{22} 23$ As expected, a low Apgar score was more common among children with adverse birth outcomes, which often correlate with childhood cancers. ${ }^{7-9} 38$ However, the elevated risks related to a low score were observed in almost all subgroups of baseline characteristics, including but not restricted to pregnancies with adverse birth outcomes. Furthermore, the associations were consistent according to country and maternal factors under investigation.

The most important strengths of our study include the prospective longitudinal design, large sample size and detailed data on other covariates. The registry system in the Nordic countries provides both a complete case ascertainment and accurate linkage with other data, which allow complete follow-up with least impact of misclassification error. ${ }^{27}$ The rarity of childhood cancer makes population-based epidemiological 
studies very difficult. Much of the heterogeneity of previous results might be due to the small sample sizes and lack of control for factors related to the child or the mother. Our data enabled us to do a more in-depth investigation by examining risks in subgroups. The cohort design based on prospectively collected high-quality data minimised the impact of information or recall bias.

One limitation of our study is that we lack information on risk factors after birth. However, factors associated with a low Apgar score, such as related neonatal treatments, may lie in the pathways between exposure and outcome, and should not necessarily be controlled for in the analyses. ${ }^{46}$ A second limitation is that we cannot rule out the confounding of factors like environmental exposures after birth. Third, the case numbers for several childhood cancers are small, although the total population included over 5 million children.

To conclude, our findings support the developmental-origins hypothesis of childhood cancer. An association between a low Apgar score and childhood cancer does not prove a causal role of the components that make up the Apgar score but strengthens the relevance of viewing the prenatal time period as a causal time window of interest. A low Apgar score may reflect a pathological pregnancy that could share causes with childhood cancers, or childhood cancers may have a clinical onset that starts during fetal life. In the first situation, a low Apgar score may also be associated with cancer risk in adulthood. In addition to being a widely accepted assessment tool in neonatal care, the Apgar score may indicate programming effects of fetal environment on further health, suggesting that its role in clinical practice and public health may reach beyond its current use.

\author{
Author affiliations \\ ${ }^{1}$ Section for Epidemiology, Department of Public Health, Aarhus University, \\ Aarhus, Denmark \\ ${ }^{2}$ Clinical Epidemiology Unit, Department of Medicine, Karolinska Institute, \\ Stockholm, Sweden \\ ${ }^{3}$ National Institute for Health and Welfare, Helsinki, Finland/Nordic School of \\ Public Health, Gothenburg, Sweden \\ ${ }^{4}$ Section for General Practice, Department of Public Health, Aarhus University, \\ Aarhus, Denmark \\ ${ }^{5}$ Research Unit for General Practice, Department of Public Health, Aarhus \\ University, Aarhus, Denmark \\ ${ }^{6}$ Research Program for Mental Child Health, Department of Public Health, \\ Aarhus University, Aarhus, Denmark \\ ${ }^{7}$ Department of Epidemiology, School of Public Health, University of \\ California, Los Angeles, USA
}

Contributors $\mathrm{JL}$ conceived the research, analysed the data and wrote the first draft of the manuscript. JL, SC, MG, MV, CO, JA and JO contributed to data analysis, interpretation of results and critical revision of the manuscript. All authors approved the final manuscript.

Funding This work was supported a grant by Dr Jiong Li from the European Research Council (ERC-2010-StG no. 260242, the European Union Seventh Framework Programme (EU FP7)); the Nordic Cancer Union (2008); the NordForsk (070331); the Danish Medical Research Council (projects no. 09-060229, 09-063494, and 09-072986); and the Swedish Council for Working Life and Social Research (Grant no. 2010-0092).

\section{Competing interests None.}

Ethics approval The study was approved by Danish Data Protection Agency (j nr. 2008-41-2680), Scientific Ethics Committee of Central Region Jylland (VEK, sagnr. M-20100252), Research Ethics Committee (EPN) at Karolinska Institutet (Ref no. 2008/4:6).

Patient consent Not needed for register-based research according to laws in Denmark and Sweden.

Provenance and peer review Not commissioned; externally peer reviewed.

\section{REFERENCES}

1. Kaatsch P. Epidemiology of childhood cancer. Cancer Treat Rev 2010;36:277-85.

2. Parkin DM, Whelan S, Ferlay J, et al. Cancer incidence in five continents VIII. Lyon, France: IARC Scientific Publications, 2002.

3. Anderson LM. Environmental genotoxicants/carcinogens and childhood cancer: bridgeable gaps in scientific knowledge. Mutat Res 2006;608:136-56.

4. Kimmel GL. An overview of children as a special populationrelevance to predictive biomarkers. Toxicol Appl Pharmacol 2005;206:215-18.

5. Garner MJ, Turner MC, Ghadirian P, et al. Epidemiology of testicular cancer: an overview. Int J Cancer 2005;116:331-9.

6. Greaves M. Molecular genetics, natural history and the demise of childhood leukaemia. Eur J Cancer 1999;35:1941-53.

7. Ma X, Metayer C, Does MB, et al. Maternal pregnancy loss, birth characteristics, and childhood leukemia (United States). Cancer Causes Control 2005;16:1075-83.

8. Tower RL, Spector LG. The epidemiology of childhood leukemia with a focus on birth weight and diet. Crit Rev Clin Lab Sci 2007;44:203-42.

9. Von Behren J, Spector LG, Mueller BA, et al. Birth order and risk of childhood cancer: a pooled analysis from five US States. Int $J$ Cancer 2011;128:2709-16.

10. Apgar V. A proposal for a new method of evaluation of the newborn infant. Curr Res Anesth Analg 1953;32:260-7.

11. Use and abuse of the Apgar score. Committee on Fetus and Newborn, American Academy of Pediatrics, and Committee on Obstetric Practice, American College of Obstetricians and Gynecologists. Pediatrics 1996;98:141-2.

12. Finster MMD, Wood MMD. The Apgar score has survived the test of time. Anesthesiology 2005;102:855-7.

13. Papile LA. The Apgar score in the 21 st century. N Engl J Med 2001;344:519-20.

14. Casey BM, McIntire DD, Leveno KJ. The continuing value of the Apgar score for the assessment of newborn infants. $N$ Engl J Med 2001;344:467-71.

15. Li J, Olsen J, Vestergaard M, et al. Low Apgar scores and risk of childhood attention deficit hyperactivity disorder. J Pediatr 2011;158:775-9.

16. Moster D, Lie RT, Irgens LM, et al. The association of Apgar score with subsequent death and cerebral palsy: a population-based study in term infants. J Pediatrics 2001;138:798-803.

17. Odd DE, Rasmussen F, Gunnell D, et al. A cohort study of low Apgar scores and cognitive outcomes. Arch Dis Child Fetal Neonatal Ed 2008;93:F115-20.

18. Stuart A, Olausson PO, Kallen K. Apgar scores at 5 minutes after birth in relation to school performance at 16 years of age. Obstet Gynecol 2011;118:201-8.

19. Sun $Y$, Vestergaard M, Pedersen CB, et al. Apgar scores and long-term risk of epilepsy. Epidemiology 2006;17:296-301.

20. Gilstrap LC III, Hauth JC, Hankins GD, et al. Second-stage fetal heart rate abnormalities and type of neonatal acidemia. Obstet Gynecol 1987;70:191-5.

21. Ekbom A. The developmental environment and the early origins of cancer. In: Gluckman P, Hanson M. eds. Developmental origins of health and disease. Cambridge: Cambridge University Press, 2006:415-25.

22. Gluckman PD, Hanson MA. Living with the past: evolution, development, and patterns of disease. Science 2004;305:1733-6.

23. Gluckman PD, Hanson MA, Cooper C, et al. Effect of in utero and early-life conditions on adult health and disease. $N$ Engl J Med 2008;359:61-73.

24. Greaves M. Childhood leukaemia. BMJ 2002;324:283-7.

25. Okasha M, McCarron P, Gunnell D, et al. Exposures in childhood, adolescence and early adulthood and breast cancer risk: a systematic review of the literature. Breast Cancer Res Treat 2003;78:223-76. 
26. Park SK, Kang D, McGlynn KA, et al. Intrauterine environments and breast cancer risk: meta-analysis and systematic review. Breast Cancer Res 2008;10:R8.

27. Frank L. Epidemiology. When an entire country is a cohort. Science 2000;287:2398-9.

28. Li J, Vestergaard M, Obel C, et al. Cohort profile: the nordic perinatal bereavement cohort. Int J Epidemiol 2010;40:1161-7.

29. Knudsen LB, Olsen J. The Danish medical birth registry. Dan Med Bull 1998:45:320-3.

30. Axelsson O. The Swedish medical birth register. Acta Obstet Gynecol Scand 2003;82:491-2.

31. Barlow L, Westergren $\mathrm{K}$, Holmberg L, et al. The completeness of the Swedish Cancer Register ГÇô a sample survey for year 1998. Acta Oncol 2009:48:27-33.

32. Gjerstorff ML. The Danish cancer registry. Scand J Public Health 2011;39:42-5.

33. Petridou E, Panagiotopoulou K, Katsouyanni K, et al. Tobacco smoking, pregnancy estrogens, and birth weight. Epidemiology 1990;1:247-50.

34. Liehr JG. Is estradiol a genotoxic mutagenic carcinogen? Endocr Rev 2000;21:40-54.

35. Law GR. Host, family and community proxies for infections potentially associated with leukaemia. Radiat Prot Dosimetry 2008;132:267-72.

36. Sadetzki S, Mandelzweig L. Childhood exposure to external ionising radiation and solid cancer risk. Br J Cancer 2009;100:1021-5.
37. Spector LG, Klebanoff MA, Feusner JH, et al. Childhood cancer following neonatal oxygen supplementation. J Pediatr 2005;147:27-31.

38. Greaves M. Molecular genetics, natural history and the demise of childhood leukaemia. Eur J Cancer 1999;35:173-85.

39. Heuch JM, Heuch I, Kvale G. Birth characteristics and risk of Wilms tumour: a nationwide prospective study in Norway. Br J Cancer 1996;74:1148-51.

40. Schuz J, Schmidt LS, Kogner P, et al. Birth characteristics and Wilms tumors in children in the Nordic countries: a register-based case-control study. Int J Cancer 2011;128:2166-73.

41. Puumala SE, Soler JT, Johnson KJ, et al. Birth characteristics and Wilms tumor in Minnesota. Int J Cancer 2008;122:1368-73.

42. Ruan K, Song G, Ouyang G. Role of hypoxia in the hallmarks of human cancer. J Cell Biochem 2009;107:1053-62.

43. Rankin EB, Giaccia AJ. The role of hypoxia-inducible factors in tumorigenesis. Cell Death Differ 2008;15:678-85.

44. Reynolds P, Urayama KY, Von Behren J, et al. Birth characteristics and hepatoblastoma risk in young children. Cancer 2004:100:1070-6.

45. McLaughlin CC, Baptiste MS, Schymura MJ, et al. Maternal and infant birth characteristics and hepatoblastoma. Am J Epidemiol 2006;163:818-28.

46. Rothman KJ, Greenland S, Lash TL. Modern epidemiology. 3rd edn. Philadelphia: Lippincott Williams \& Wilkins, 2008. 